\title{
Implementation of English Language Education Policy in Hong Kong Kindergartens: Perspectives of Stakeholders
}

\author{
Xun Lu \\ School of Politics and Public Administration, East China University of Political Science and Law, \\ Shanghai, 201700, China, \\ 18072601122@ecupl.edu.cn
}

\begin{abstract}
After Hong Kong's handover in 1997 and under the "one country two systems" model, education in Hong Kong underwent tremendous changes. Since then, there has been a heated debate about how English language education policy ought to be designed and promoted in Hong Kong. This paper chooses Hong Kong kindergartens as the setting of the study and uses a qualitative analysis tool. This paper explores (1) the situation of English language education in Hong Kong Kindergarten Education; (2) the implementation of English language education policy in Hong Kong kindergartens; (3) the challenges in the practical promotion of English language education policy in Hong Kong kindergartens. Based on the stakeholder theory, findings indicate that different requirements shown by stakeholders about curriculum design, teaching method, and education goal are the major factors of the tension between policies and practices. Policymakers' intentions, schools' standards, teachers' competencies and beliefs, and parental influence all impact the implementation process.
\end{abstract}

Keywords: English language education, implementation of policy, stakeholder theory, Hong Kong kindergartens

\section{INTRODUCTION}

Hong Kong, a coastal city in southern China, $92 \%$ of its population is ethnic Chinese and $88.9 \%$ of the people are speaking Cantonese (a Chinese dialect) as their first language[1]. After Britain handed over Hong Kong to China in 1997, the Hong Kong government proclaimed Hong Kong as a Special Administration Region.

Over more than two decades, Hong Kong has still kept its distinction in language priorities and language policy. During the period in which Hong Kong is a colony of Britain, English was the official language while Cantonese was the medium of instruction in kindergartens and primary schools. Since Mainland China reclaimed control over Hong Kong, the importance of Putonghua, China's national language, has grown significantly, and Putonghua has become the medium of teaching at all levels of education. Based on the real-life scenario situations, the Hong Kong Administration Region Government (HKSARG) has advocated a "biliteracy and trilingual" language strategy to encourage individuals in Hong Kong to be proficient in writing Chinese and English, as well as spoken English, Cantonese, and Putonghua.

The changing priority of language in language policy formation and implementation has been argued to be affected by a multitude of factors from political, social, cultural, and economic forces [2][3][4] to the agency and interpretation of various agents [5]. There is a need to analyze the changes before and after the implementation of policy and seek the factors influencing the changes.

Previous studies have examined colonial and/or post-colonial patterns in English language teaching in primary and secondary schools[6][7][8]. However, little has provided an analysis of policies and practices of English language education in the preschool sector. Moreover, there is little research based on the perspectives of stakeholders (e.g. government, policymakers, parents, teachers and schools). This study, therefore, aims to evaluate the implementation of English language education policy in Hong Kong 
kindergartens in terms of the stakeholders. This research evaluated and assessed the circumstances of English language education policy in Hong Kong kindergartens based on a qualitative examination of government papers and empirical data. Furthermore, classroom practices were analyzed to determine the situation of English language learning in Hong Kong Kindergarten. After comparing the language policy goals with the implementation of policies, the stakeholder theoretical model, which highlights the involvement of different agents in the implementation of language policy was attempted to analyze the factors of the tension between policy and practice.

\section{ANALYSIS OF THE SITUATION OF HONG KONG KINDERGARTEN EDUCATION}

\subsection{English language education policies in Hong Kong kindergartens}

Before the handover, language education in the preschool sector was not the focus of the Hong Kong Special Administration government. It was not until the 1970s that policy documents on language education in kindergartens were clear [9][10][11]. However, even if language education becomes important in kindergartens, English is not suggested as a formal topic, in contrast to Cantonese, the mother tongue of most young children, which was picked as the priority for Hong Kong's kindergartens shortly after Britain's handover. The Standing Committee on Language Education and Research, for example, recommended in 2003 that "preschools should give English or Putonghua exposure to their pupils only if the instructors they deploy fulfill the Language Proficiency Requirement for English or Putonghua teachers in speaking."[12]

The principle of learning English, according to the updated Guide to the Pre-Primary Curriculum 2016, is to enable children to "develop an interest in learning English, listen to and understand simple dialogues in everyday life, sing or recite nursery rhymes, and apply simple terms."[13] The key teaching objectives of English language education, according to the most recent Kindergarten Education Curriculum Guide, are to encourage children's interest and confidence in English while also developing basic English skills.[14] Drilling, spelling, and memorization, as well as a one-way lecture-based teaching style, are discouraged when teaching children English. Instead, policymakers seek to pique children's interest in English and anticipate that they will be able to learn English in authentic and enjoyable settings such as singing songs and rhymes, having discussions, telling stories, playing games, and so on.

\subsection{English language education practices in Hong Kong kindergartens}

In kindergarten classes, kid-centered and activity-based approaches have been used to comply with the guideline. Oral discussions, storybook read-aloud, singing, for example, were utilized in the teaching and learning of English in 148 kindergartens in Hong Kong, according to Wong.[15] As for the financial and professional support, in 2005, the Language Fund received HK\$200 million to provide overseas immersion programs and organized support to preschool and elementary school English language teachers.[16] In the period of 2007 to 2008, The Standing Committee on Language Education and Research (SCOLAR) provided professional assistance to approximately 290 kindergartens and 800 teachers in the upgrading of curriculum guides and teaching methods.[17]

However, there are still a lot of differences between policy documents and classroom practice. Although the Pre-primary Curriculum Guidelines 2006 did not recommend any 'formal' instruction for English language learning, activities still exist. Gao and Ma discovered in quantitative research that whether in-service English instructors or pre-service ones in Hong Kong tended to favor memorization-related beliefs in vocabulary acquisition and that dictation is a common means of learning vocabulary in Hong Kong.[18] The primary modes of English learning, according to $\mathrm{Ng}$ and Rao, were textbooks and conventional paper and pencil exercises.[19]

The instructional time of English is also quite different from one kindergarten to another in Hong Kong. According to research, English learning activities can span from around fifteen minutes to five hundred and thirty-six minutes, with two to five instruction sessions each week.[19] Kindergartens that charged higher tuition are more likely to have increased teaching time for English and more frequent use of ways of storytelling. Furthermore, there is a big difference in the eligibility and credential of teachers. The English teachers in Hong Kong kindergartens are a combination of NETs and/or non-native English-speaking teachers (NNESTs)[20]. It can be seen that some NETs that neither hold qualifications in early childhood education nor in TESOL/TEFL and some NNESTs that have low levels of English proficiency and have no formal training in English language teaching.

\section{FACTORS OF DIFFERENCE BETWEEN POLICY AND PRACTICE: FROM THE PERSPECTIVE OF STAKEHOLDERS}

\subsection{Parents}

Parents' perception in English language education 
should be taken into account in analyzing the tension between policy and practice due to the significant role in children's education. Although English is officially taught beginning in first grade in Hong Kong, parents still have a strong preference for English language instruction in much more early years. Parents in Hong Kong consider that learning English can be more beneficial to their children compared with Cantonese and Chinese. In their eyes, English has been credited with promoting upward social mobility and positioning Hong Kong as a worldwide financial and business hub.[7]

As a result, reform of the academic English curriculum is demanded by parents so that their children can prepare for primary schooling [21]. Parents also exert pressure on kindergartens to provide children with skill-based practices including drilling, spelling, memorizing, and handwriting, which are in conflict with the Hong Kong government's pre-primary education strategy guide's aims.

\subsection{Teachers}

Teachers' educational level, teaching training background and English proficiency are critical elements of classroom practices. As evaluated in research, teachers with greater academic qualifications and English teaching experience are more inclined to teach preschool children English with vocabulary building activities, such as oral discussions, storytelling, and reading aloud when compared to those with a lower academic degree[20]. However, in recent years, the level of teacher competence and skill in Hong Kong kindergartens has been highly criticized because the minimum requirement for becoming a kindergarten teacher only needs a one-year certificate in ECE, which means that teachers without qualification in early childhood education or formal training in the English language teaching are recruited.

Besides teachers' educational level, teachers' beliefs towards classroom teaching also affect classroom practices. After the activity-based language policy is implemented, teachers' concerns on classroom management and apparent conflicts between the teaching style and teacher performance assessment have risen[20]. Continuous assessment is used by certain schools to improve teaching and learning outcomes, which makes teachers worry about their final evaluation of teaching quality and prompt them to use the traditional way of teaching such as drilling, spelling to ensure a good outcome.

\subsection{Kindergartens}

The difference between policies and practices of English language education in kindergartens is also associated with school priority and teaching resources in language education. Although English learning is accessible at a preschool stage, English is not the language of top priority in most local kindergartens. Kindergartens can choose their teaching and learning methods based on the teaching funds and proficiency levels of language teachers. Without financial and professional support from relevant organizations, some of the kindergartens would have no sufficient funding to hire a highly qualified teacher or carry out high-level English teaching[20]. Besides, in view of the incessant pressure from parents, kindergartens with lower funds often have no choice but to make concessions since parents' selection of kindergartens affected their foundation and operation.

The difference between teachers' competencies and teaching quality also shows that the hiring of English teachers is either selected by kindergartens or private employment agencies entrusted by kindergartens. Therefore, it results in apparent discrepancies between kindergartens that hire teachers without qualifications in TESOL/TEFL and that select highly-educated TESOL/TEFL holders.

\subsection{HKSARG}

As a survey done by Center for Communication and Public Opinion indicates, many Hong Kong People define themselves as disparate from mainland Chinese, or even as non-Chinese.[22] This poses threat to Hong Kong Special Administration Region Government (HKSARG) that shows affinity to mainland China. HKSAR government is wary of citizens' lack of awareness and appreciation of the mainland situation. Chinese medium instruction policy has been promoted aiming at consolidating the national identity and national pride among Hong Kong citizens. Besides, in order to respond to the globalization and the widespread usage of English, HKSRG lay emphasis on English language education and promote the 'bi-literacy and trilingual' language policy so that students in Hong Kong can get into a good university which is often taught with the medium of English and enhance personal competitiveness in the workplace. What is more, given that children in kindergartens are still at the early age of learning and most of them are impressionable, play-based pedagogy is recommended for English language education in kindergartens in order to avoid killing children's interest in subsequent learning in English compared with traditional skill-based approaches demanded by parents.

\section{DISCUSSIONS}

This paper tried to analyze the causes of the difference between English language education policies and practices in Hong Kong's kindergartens. The status of English language education in the kindergarten sector 
is tightly related to the policymakers' intention, schools' standard, teachers' beliefs, and competencies and parental influence. The interplay of various factors led to tension between policy and practice. It reveals that English remains the preferred language in Hong Kong even if the government spares no effect to promote Chines and Cantonese in order to uphold the national and local identity.

As English language instruction in kindergarten is getting increasing attention, English language teaching and learning in the kindergarten sector in Hong Kong face unprecedented demands. First, there are diverse views from stakeholders in English language learning in kindergartens. Second, there is a discrepancy between language teachers in competencies and credentials. Third, there are no uniform criteria in English language teaching in kindergartens from teaching content to curriculum design to mode of instruction. These are often left to the discretion of kindergartens.

\section{CONCLUSION}

In conclusion, there needs to do some changes in English language education in Hong Kong kindergartens due to the high demand for English teaching. However, how to support and who to support needs to be considered carefully. In view of most kindergartens' yield to parents' aspiration due to parents' great influence on funding resources, Hong Kong Special Administration Region Government have the duty to re-think the subsidy policy and provide much more financial support to enhance the discretion of kindergartens in pedagogy. Well-educated and well-trained teachers are crucial elements in English language teaching. In view of the great discrepancy in teachers' education background, policymakers should formulate policy and kindergartens should provide regular training to enhance the degree level of kindergarten teachers. Professional training for both NET and NNEST is necessarily needed. In view of the huge difference in teaching content and teaching methods in disparate kindergartens, policymakers also need to specifically articulate the standard of teaching content and methods in English language teaching, seeking common ground while reserving differences.

This study attempts to analyze the tension of English language teaching between policymaking and classroom practice from the perspective of stakeholders. The empirical study has qualified the school settings without distinguishing public kindergartens from private kindergartens. Furthermore, the study has limitations in quantitative measures to further validate the qualitative findings. A large sample size of stakeholders is also needed to provide additional insights due to the widespread influence of English language policy and various agents affected by the policy in Hong Kong. Future research might include an extension to the scale of stakeholders to further study the factors of tension. Research that is based on the quantitative tool is also required to probe into the impacts of policy implementation. Furthermore, cross-cultural comparative studies and comparative studies of private and public kindergartens are needed to explore the different patterns of implementation of English language education policy.

\section{REFERENCES}

[1] Hong Kong Census and Statistics Department (2016). Summary results of 2016 Population Census. Retrieved September 2, 2021 from https://www.censtatd.gov.hk/sc/scode459.html.

[2] Baldauf Jr., R. B. (2006). Rearticulating the case for micro language planning in a language ecology context. Current Issues in Language Planning, 7(2-3), 147-170. https://doi.org/10.2167/cilp092.0.

[3] Cooper, R. L. (1989). Language planning and social change. Cambridge University Press.

[4] Spolsky, B. (2004). Language policy. Cambridge University Press.

[5] Ricento, T. K., \& Hornberger, N. H. (1996). Unpeeling The Onion: Language planning and policy and the ELT professional. TESOL Quarterly, 30(3), 401-427. https://doi.org/10.2307/3587691.

[6] Bolton, K. (2011). Language policy and planning in Hong Kong: Colonial and post-colonial perspectives. Applied Linguistics Review, 2, 51-74. https://doi.org/10.1515/9783110239331.51.

[7] Evans, S. (2017). Language policy in Hong Kong education: A historical overview. European Journal of Language Policy, 9(1), 67-84. https://doi.org/10.3828/ejlp.2017.5

[8] Poon, A. Y. K. (2010). Language use, and language policy and planning in Hong Kong. Current Issues in Language Planning, 11(1), 1-66. https://doi.org/10.1080/14664201003682327

[9] Education Department. (1994). Manual of kindergarten practice. Government Printer.

[10] Education Department. (1999). List of do's and don'ts for kindergartens. Government Printer.

[11] Curriculum Development Council. (2000). Learning to learn: The way forward in curriculum development. Government Printer.

[12] Standing Committee on Language Education and Research. (2003). Final report: Action plan to raise language standards in Hong Kong. Government Printer. 
[13] Curriculum Development Council. (2006). Guide to the pre-primary curriculum. Government Printer.

[14] Curriculum Development Council. (2017a). English language education: Key learning area curriculum guide (primary $1-$ secondary 6). Government Printer.

[15] Wong, R. K. S. (2016). Do Hong Kong pre-school teachers of English engage in learning and teaching activities conducive to young children's vocabulary development? In V. A. Murphy, \& M.Evangelou (Eds.), Early childhood education in English for speakers of other languages (pp.195-206). British Council.

[16] Legislative Council Panel on Education. (2005). Use of language fund -proposals to strengthen support in language education at pre-primary and primary levels (LC Paper No. CB (2) 1429/04-05 (01)).

https://www.legco.gov.hk/yr04-05/english/panels/e d/papers/ed0509cb2-1429-1e.pdf.

[17] Legislative Council Panel on Education. (2015). Issues related to the Chinese and English proficiency of students and the policy on fine-tuning of the medium of instruction for secondary schools (LC Paper No. CB (4)321/15-16 (01)).

https://www.legco.gov.hk/yr15-16/english/panels/e d/papers/ed20151214cb4-321-1-e.pdf

[18] Gao, X., and Q. Ma. 2011. "Vocabulary Learning and Teaching Beliefs of pre-Service and in-Service Teachers in Hong Kong and Mainland China." Language Awareness 20 (4): 327-342.

[19] Ng, M. L., \& Rao, N. (2013). Teaching English in Hong Kong kindergartens: A survey of practices. The International Journal of Literacies, 19(3), $25-47$. https://doi.org/10.18848/2327-0136/CGP/v19i03/4 8780 .

[20] Carrie Lau (2020): English language education in Hong Kong: a review of policy and practice, Current Issues in Language Planning, DOI: 10.1080/14664208.2020.1741239.

[21] Leung, C. S. S., Lim, S. E. A., \& Li, Y. L. (2013). Implementation of the Hong Kong language policy in pre-school settings. Early Child Development and Care, 183(10), 1381-1396. https://doi.org/10.1080/03004430.2013.788816.

[22] Centre for Communication and Public Opinion Survey The Chinese University of Hong Kong. (2016). Public evaluation on media credibility. Retrieved
http://www.com.cuhk.edu.hk/ccpos/b5/research/Cr edibility_Survey\%20Results_2016_CHI.pdf. 